\title{
Appearance Esteem Trajectory According to Three Different Sources of Support Among Adolescents Over a School Year
}

\section{Abstract}

Although social support has been linked to body satisfaction, there has been little research on the effect of differential sources of support on the trajectory of appearance esteem over time. To address this gap, this study explored changes in adolescents' appearance esteem to perceived social support over one year. Data were collected from 339 Canadian adolescents $(54.57 \%$ females $)$ in Grade $7\left(M_{\text {age }}=12.05\right)$ and Grade $10\left(M_{\text {age }}=15.14\right)$. Multilevel growth modeling revealed that perceived social support from fathers was not associated with appearance esteem, whereas mothers' support had the strongest effect on appearance esteem, consistently over time. Friends' support was also related to an increase in the appearance esteem trajectory, but only for older students. Overall, this prospective study provides a better understanding of the unique contribution of three different sources of social support during adolescence for preventing negative appearance esteem, beyond the effects of other related variables.

Key words: adolescence; body esteem; body image; peer support; parental support; multilevel growth modeling 


\section{Introduction}

Body image is particularly important during the critical period of adolescence (Bucchianeri et al., 2013), in which concerns about the body tend to increase while lifestyles and physical and psychosocial health are developing (Littleton \& Ollendick, 2003). Among adolescents, low levels of body image can lead to various negative psychological outcomes (Duchesne et al., 2017), problematic weight-related behaviors, and maladaptive appearance management behaviors (López-Guimerà et al., 2013). As these consequences can last in the long term, focusing on protective factors of negative body image is crucial (Cash, 2012). Among those factors, concerns about appearance among adolescents have been the object of increased public interests in recent years (Ricciardelli \& Yager, 2016). However, few studies have focused specifically on appearance esteem, an important sub-construct of body image that refers to general feelings about appearance (Mendelson et al., 2001). It is well known that social interactions are important protective factors for body image among adolescents (Ata et al., 2007). However, little is known about the respective influence of various sources of support on appearance esteem and its trajectory. Given that interpersonal relationships are critical for helping adolescents cope with psychological distress occurring during this developmental period (Camara et al., 2014), this prospective study extends previous research by assessing the differential impact of three important sources of perceived social support on the trajectory of adolescents' appearance esteem over a 12month period using a robust statistical approach.

\section{Appearance Esteem}

Whereas body image is defined as individuals' beliefs, thoughts, feelings, attitudes, and behaviors toward the body (Pruzinsky \& Cash, 2002), appearance esteem is an important part of the multidimensional and complex construct of body image and refers to general feelings about appearance (Mendelson et al., 2001). During adolescence, concerns about appearance become very important because of the numerous physical and psychological changes occurring (Mendelson et al., 2001). Adolescents may be subject to considerable pressure about their appearance from their family, their peers, and the media (Hardit \& Hannum, 2012) and they may also be particularly afraid of being criticized or evaluated negatively by others (Beesdo et al., 2007). In fact, in a qualitative study where adolescents were asked to report factors related to the development of body dissatisfaction, many emphasized appearance teasing, appearance pressure, appearance-related conversations, and appearance comparison (Gattario \& Frisén, 2019). As appearance esteem is associated with identity development (Wängqvist \& Frisén, 2013), it seems paramount to explore its protective factors to help promote better adjustment and mental health during this critical period of life. 
The few studies focusing specifically on the appearance esteem trajectory have shown that it tends to exhibit a

49

50

51

52

53

negative transition from childhood to adolescence for both genders, with a greater decrease among girls and those with a higher body mass index (BMI) (Frisén et al., 2015), and then to stabilize in adulthood (Nelson et al., 2018). This finding is consistent with those on body dissatisfaction where predictors from adolescence to middle adulthood would be gender, age, BMI, and other variables, such as depression, self-esteem, parental communication and caring, peer dieting, and weight-based teasing (Wang et al., 2019).

Given that many individual and environmental factors can influence body dissatisfaction, it may be difficult to specifically identify the role of each variable on its trajectory, as suggested in findings from the longitudinal study by Wang et al. (2019). That study revealed several differences in the evolution of body dissatisfaction over time even if, overall, it remained relatively stable from middle adolescence to adulthood. Their findings suggested that self-image and thus body satisfaction develop at an early age, hence the importance of ensuring positive appearance esteem in adolescence to prevent problems in the short and long term. However, no known studies have focused on the protective factors that specifically influence the trajectory of appearance esteem.

\section{Social Interactions and Social Support}

The important role of the social environment in appearance concerns has inspired many sociocultural models, such as the Bowlby attachment model (Bowlby, 1978) and the tripartite influence model of body image and eating disturbance (Thompson et al., 1999). The theoretical model used for this study was the acceptance model (Avalos \& Tylka, 2006), according to which a person's body appreciation is strongly influenced by the appreciation that loved ones have of their own body and by the social support that they provide. This association has repercussions from adolescence to adulthood (Gattario \& Frisén, 2019). One way to explore social influences in research is to investigate social support. Feeling accepted and appreciated by others would make people more confident and give them more positive feelings about themselves and their body (Stice \& Whitenton, 2002).

Within adolescents' social groups, parents are important to consider in relation to body image. For example, some aspects of parenting, such as attachment style and perceived parental care and control, are associated with body esteem, self-esteem, and eating behaviors among young adult males and females (Sira \& White, 2010). Furthermore, in a 15-year study including 1,455 participants, Wang et al. (2019) found that environmental factors, such as parental caring and communication, can be important predictors of body dissatisfaction from adolescence to adulthood. Besides verbal communication and active encouragement, even indirect behaviors, such as mothers exhibiting body image 
76

77

concerns, have been found to impact the appearance esteem of offspring (Handford et al., 2018). Parent-adolescent relationships are thus important for the maintenance of a healthy body image and can be conceptualized as a protective factor. However, whereas the mother-child relationship has been examined in many studies and a maternal influence has been consistently found, little is known about the distinct role of fathers. This gap has been highlighted in previous research (Sira \& White, 2010), suggesting the need for more investigation of the respective contribution of every dimension of family functioning. Moreover, research is needed to include additional information in the acceptance model about whether and how support from others plays a role in increasing appearance esteem.

In adolescence, the social environment consists primarily of interactions with school peers, such as classmates and friends (Brown et al., 2008), who play a significant role in appearance esteem among girls and boys. Adolescents are more frequently confronted with peers' appearance cultures and with an integrated focus on appearance, beauty, and thinness (Jones et al., 2004), which are associated with body image concerns and negative behaviors (Carey et al., 2013). Thus, given that relationships with peers substantially influence body appreciation and that friends are very present in adolescents' lives, it is important to gain a deeper understanding of the role of support received more specifically from friends (Kenny et al., 2017).

The respective influence of peers and of friends on appearance esteem in adolescence varies. The results of a meta-analysis of 25 studies conducted between 1995 and 2010 among adolescents and young adults revealed a stronger relationship between body dissatisfaction and the influence of peers than of family (Quiles Marcos et al., 2013). However, this meta-analysis grouped studies pertaining to parental and peer/friend support, and few focused on both types at the same time. Nonetheless, the greater importance of friends could be explained by the notion that adolescence is the developmental period in which emancipation from parents occurs alongside individualization, leading the person to become a full-fledged autonomous adult (De Goede et al., 2009). In preadolescence, boys and girls spend more time socializing with family than in later adolescence, when they tend to spend more social time with same-sex peers (Graber et al., 1999). In early adolescence, boys and girls both perceive more support from their mother and their father than in late adolescence (De Goede et al., 2009). Thus, regarding body image, it may be expected that, in later adolescence, parental influence on appearance esteem would be less strong than peer influence. However, previous studies have produced conflicting results. For example, among young university students, body esteem would be greater for students who felt loved by, in order of importance, their mother, another family member, their friends, and, lastly, their father (Merianos et al., 2012). Another longitudinal study conducted among adolescents, which was 
104

105

106

107

108

109

110

111

112

113

114

115

116

117

118

119

120

121

122

123

124

125

126

127 not included in the Quiles Marcos et al. (2013) meta-analysis, revealed that peer support deficits exhibited only a marginal negative relationship with body esteem whereas parental support deficits were negatively associated with body esteem for both boys and girls (Bearman et al., 2006). Moreover, a previous longitudinal study conducted among Canadian adolescents revealed that social support from both family and friends had a similar effect on appearance satisfaction (Cantin \& Stan, 2010). As most studies included in the Quiles Marcos et al. (2013) meta-analysis were cross-sectional and did not consider the mother and father separately, these findings highlight the importance of conducting further studies to better understand whose influence on appearance esteem is stronger during the critical developmental period of adolescence.

Regarding mothers' and fathers' differential roles, mothers can be expected to have more influence on their adolescents' appearance esteem because mothers’ body dissatisfaction problems and eating disorders are often associated with those of their children (Handford et al., 2018). Moreover, it appears that in adults, women are more likely than men to fall prey to these problems (Fallon et al., 2014). Previous research has also suggested that adolescents are more influenced by their mothers' comments and body concerns than those of their fathers, and that daughters have more negative outcomes than sons (Kluck, 2010).

Parents’ comments are not the only ones related to appearance esteem. Peer groups’ behaviors, such as negative comments or teasing, which are common during adolescence, can have harmful effects (Eisenberg et al., 2017). These actions are associated with higher levels of negative outcomes, such as increased risks for negative emotional wellbeing and unhealthy behaviors (Eisenberg et al., 2003), and can lead to body dissatisfaction (Wang et al., 2019). Family and peers were both found to make negative weight-related comments, which can lead to a detrimental cumulative risk (Eisenberg et al., 2003). For example, having friends who make disparaging remarks about their own appearance or that of others has been reported to increase the risk of body dissatisfaction and unhealthy weight-control behaviors (Cantin \& Stan, 2010). Indeed, negative weight-related comments can be expected to have detrimental effects on appearance esteem among adolescents. Thus, to provide a better understanding of the effect of social support on appearance esteem, it is important to control for the possible influence of negative weight-related comments.

\section{Current Study}

Although previous research has highlighted the importance of social influences in the body image field, there is a need to investigate the respective effects of parents' and friends' support on adolescents' appearance esteem trajectory over time, an important construct of body image for adolescents that has been less studied. This article 
sought to address this gap in the literature by focusing on the role of three sources of social support in appearance esteem among Grade 7 and Grade 10 students over a one-year period. It also extended previous research by clarifying the fathers' contribution to their offspring's body image. The results could help improve preventative programs based on positive body image and protective factors. The current study had two main objectives. The first was to investigate the relationship between social support from the mother, father, and friends and appearance esteem. In line with the acceptance model (Avalos \& Tylka, 2006) and with prior research (Quiles Marcos et al., 2013), it was expected that social support from the mother, father, and friends would be related to the participants' appearance esteem for both grades. More specifically, it was hypothesized that mothers' influence would be stronger than that of fathers, and that relationships between social support and appearance esteem would be stronger among older adolescents when social support was derived from friends rather than from parents, while the opposite pattern was expected among younger adolescents. The second objective was to explore the contribution of demographics on the progression of appearance esteem over one year. Based on previous work by Mendelson et al. (2001) and Frisén et al. (2015), it was hypothesized that appearance esteem would be higher among Grade 7 students (early adolescence) than among Grade 10 students (middle adolescence) and that there would be a gender-based effect, in which females were expected to report lower appearance esteem than males.

\section{Methods}

\section{Participants}

Data used in this study were selected from a project, involving 740 respondents, in which the Healthy Mind, Healthy Body (HMHB) program was evaluated. For that project, participants came from two high schools of similar socioeconomic backgrounds and were randomly assigned either to the experimental condition consisting of healthrelated interventions or to the control group. To achieve the aim of the current study, only the subsample of students from the control group (who did not receive any intervention and who had no contact with the experimental group; $\mathrm{N}=427$ ) was selected. To ensure complete anonymity of the participants' answers and to match their questionnaires at each follow-up (from T1 to T3), students answered the same questions about their identity at each wave, so they did not have to remember their code (the two first letters of their first name, their birthdate, etc.), generating an eightcharacter identification code (Yurek et al., 2008). All students who were present during each of the data-collection visits and who consented to participate in the study were included in the current sample. Participants in Grade 7 were required to submit a parental consent letter to complete the survey, but this was not required for those in Grade 10, 
160

161

162

163

164

172 Table 1.

173

because Quebeckers can provide informed consent at 14 years of age. Overall, the research sample was composed of 339 students at baseline. The phenomenon of attrition is almost inevitable in longitudinal studies, and the current data are no exception. At T2, 260 participants were still enrolled in the study and completed the survey, a loss of 23\%, and at T3, 240 completed it, a loss of 30\%. The logistic regression showed that dropout variation was not related to any of the variables included in the current study. These findings indicate that the missingness was random.

Approximately half of the participants at baseline $(\mathrm{N}=167,49.3 \%)$ were Grade 7 students in early adolescence ( $M_{\text {age }}=12.05$ years, $\left.S D=0.24\right)$ and the other half $(\mathrm{N}=172,50.7 \%)$ were Grade 10 students in middle adolescence $\left(M_{a g e}=15.14\right.$ years, $\left.S D=0.36\right)$. There were 154 males $(45.4 \%)$ and 185 females $(54.6 \%)$. As for their ethnicity, $95.3 \%$ were Caucasian, 3.8\% were from First Nations, 5.6\% were from Western Europe, 2.1\% were from North Africa/Middle East, and 5.9\% indicated another ethnic/racial background. A quarter (25.1\%) of the participants reported experiencing food insecurity (e.g., their families could not afford to eat balanced meals), an indicator of low socioeconomic status (Daveluy et al., 2001). Baseline sociodemographic data of the study population are shown in Procedure

There were three waves of data collection. Time 1 took place at the start of the school year (T1: October 2016), Time 2 at the end of the school year (T2: May 2017), and Time 3 at the beginning of the next school year (T3: October 2017). Parents and students received a letter describing the study. They answered a custom-designed questionnaire with different scales at baseline (T1) and at the 8- and 12-month follow-ups (T2 and T3). The questionnaire was administered in computer rooms during regular class hours. This study received the institutional review board's (IRB) approval (blinded for review).

\section{Measures}

Appearance esteem. The Body-Esteem-Appearance subscale of the Body-Esteem Scale (Mendelson et al., 2001) was used. It consists of 10 Likert-scale items assessing general feelings about appearance. Participants were instructed to report how much they generally appreciated their body (e.g., "I like what I see when I look in the mirror") by giving a score from 0 (never) to 4 (always), where a higher score indicated positive appearance esteem. Standardized Cronbach’s alpha values in the sample were 0.933 at T1, 0.932 at T2, and 0.934 at T3.

Perceived parental support. Parental support was measured at T1 through the Parental Emotional Support Questionnaire (Deschesnes et al., 997) based on the questionnaires developed by Schaefer (1965), Siegelman (1965), 
and Parker, Tupling, and Brown (1979). The adolescents were required to complete one questionnaire concerning their mother and another one concerning their father (it was the same questionnaire apart from the instruction: Answer the following questions while thinking of your father/while thinking of your mother). Support was assessed according to a four-item Likert-type scale ranging from 0 (never) to 5 (often), for example: Is he affectionate with you (e.g., takes you in her arms, smiles at you, kisses you or talks to you kindly). The scores were added together for a maximum total of 15. Higher scores indicated greater social support. In cases where the students had little or no contact with one or both biological parents, they completed a questionnaire referring to the female and male adults whom they considered to play these roles (stepparent, adoptive parent, grandparent, etc.). The adolescents were not asked who the person was; however, a sociodemographic question on family composition provided the information needed to make this determination. According to this question, $85.1 \%$ of the participants in the sample lived with their biological father and mother, $10.0 \%$ with their mother and her partner, $2.5 \%$ with their father and his partner, and 2.4\% in other situations (guardian, foster family). Standardized Cronbach's alpha values for maternal and paternal support in the current study were 0.739 and 0.788 , respectively, and the correlation between those two variables was $0.519(p=$ $0.000)$.

Perceived friends' support. Friends' support was measured at T1 using four items developed by Zimet, Dahlem, Zimet, and Farley (1988) on a 7-point Likert-type scale ranging from strongly disagree (0) to strongly agree (6). Examples of these items are "I can count on my friends when things go wrong" and "I can talk about my problems with my friends.” Higher scores indicated greater support from friends. The standardized Cronbach’s alpha was 0.876 in the current sample.

Perceived current figure. Perceived current figure was evaluated with the Figure Rating Scale (Collins, 1991), generally used to determine participants' desire to change their figure by calculating the gap between the perceived and ideal figures. Participants were instructed to assess which figures were closest to their own from a selection of seven silhouettes, ranging from smallest to largest. In accordance with the aim of the present study, the analyses included the perceived figure responses only as a measure of perceived body size in replacement of BMI, as the two are strongly correlated (Gardner \& Brown, 2010). BMI was calculated in this study but could not be included because of the high level of missing data (35.54\%) for either weight or height. Because the correlation between the BMI and perceived figure was significant $(r=0.580, p<0.001)$ among the respondents, perceived figure was deemed appropriate for use as a control variable. 
Weight-related teasing. The degree and source of the weight-related negative comments received by the participants were assessed at baseline using an adapted version of the nine items developed by Bellerose (2002). Participants answered the question, "Do the following people (e.g., mother, father, boyfriend/girlfriend, siblings, friends, extended family, sport teacher or coach, ex-boyfriend/ex-girlfriend, or other) ever make negative comments about your weight?” A score (from 0 to 9) indicating the number of sources of negative comments received at some point in their lives was calculated. In the present sample, $47.5 \%$ of respondents reported having previously received negative comments about their weight, and 1.5\% had received negative comments from between six and nine different sources $\left(M_{\text {Sources of teasing }}=1.16, S D=1.62\right)$.

Sociodemographic characteristics. Participants were asked to provide sociodemographic information including gender, grade level, ethnicity, and food insecurity.

\section{Statistical Analyses}

Before the main analysis was conducted, demographics and descriptive statistics were computed. Longitudinal multilevel growth modeling (Grimm et al., 2017) was then conducted to investigate the association between social support and the appearance esteem trajectory. This type of analysis has been proven to allow the examination of individual differences in within-person variations and co-variations over time (Hoffman, 2007). Given the three measurement waves (Burchinal et al., 2006) and the small amount of missing data (Enders, 2011), the sample size provided sufficient statistical power to detect slope differences between groups even for small effect sizes (Coertjens et al., 2017). Moreover, according to Arend and Schäfer (2019), the power estimation of this two-level model study is considering as sufficient. First, the mean trajectory of appearance esteem across the three time points was modeled (to determine if it increased, decreased, or remained the same over time). Second, the effects of predictors measured at T1 on appearance esteem were examined. Gender, students’ grade level, current perceived figure, and negative weight-related comments were included as control variables in the current model. Food insecurity was not significant and thus not included in the final model for the sake of parsimony. A widely used software program for studying data with hierarchical or nested structures, SAS (version 9.4), was used (Bell et al., 2013).

The three social support variables were centered-reduced, which made their coefficients comparable. Full

242 It is comparable to multiple imputation and is considered to produce stable, more efficient, and less biased estimates of the parameters of interest (Johnson \& Young, 2011). 
Singer and Willett's (2003) multiple-step procedure, described below, was used to test hypotheses. First, an unconditional model was computed (with no predictors). Second, a series of nested multilevel models was fitted. The effect of each predictor, added sequentially, was tested on the intercept (baseline) and on the rate of change (time). Then, alternate models including the interactions between the variables, or with time, were tested. To select the best final model, fit indices, such as the Akaike information criterion (AIC), the Bayesian information criterion (BIC), and the log-likelihood (deviance) statistics, were used (Grimm et al., 2017). Lower values indicated a better representation of the data by the model (Singer \& Willet, 2003). The difference in deviance between the unconditional model and the final conditional model, which is a measure of goodness of fit, was $\Delta \chi^{2}=235.1, \Delta d l=23, p<0.001$. This justified the decision to retain this model to represent the rate of change in appearance esteem. Finally, the examination of conditional residues indicated no major violation of the postulates of normality and homoscedasticity.

\section{Results}

\section{Descriptive Statistics}

Descriptive statistics and correlations among the variables are presented in Table 1. All the correlations appeared to be in the hypothesized directions.

\section{INSERT TABLE 1 ABOUT HERE.}

\section{Appearance Esteem and its Trajectory}

Appearance esteem trajectory. Results of the unconditional growth model revealed that the intraclass correlation was 0.77 , justifying the use of conditional multilevel analyses. This finding indicated that students' appearance esteem score variance was attributable mostly to differences between, rather than within, participants over the 12-month period.

Predicting appearance esteem at baseline. The parameter estimates for each of the predictors in the final model are listed in Table 2. In order of importance, mothers' and friends' support had unique and significant effects on the appearance esteem subscale at baseline $(\beta=0.194, p=0.015$ and $\beta=0.141, p=0.024$, respectively), while fathers' support appeared to be non-significant $(\beta=0.119, p=0.142)$. This meant that higher levels of social support from the mother and friends were associated with higher levels of appearance esteem at T1. Because the estimate for social support from mothers was higher than for social support from friends $(\beta=0.194$ and $\beta=0.141)$, these results also suggested that the effect of social support from the mother was more important than that of social support from friends. These effects were significant above and beyond the effect of the control variables, which were also all related 
272 to appearance esteem. However, the appearance esteem association with social support from the father was not

273 significant. As for the control variables, gender and grade were associated with more positive appearance esteem ( $\beta=$

2740.658 and $\beta=-0.383$, respectively, $p<0.001$ ), in the sense that being a boy and being in Grade 7 was associated with

275 better appearance esteem. Moreover, lower appearance esteem was associated with larger self-perceived figure ( $\beta=$ -

$2760.137, p<0.001$,) and a higher number of sources of negative weight-related comments $(\beta=-0.070, p<0.05)$.

INSERT TABLE 2 ABOUT HERE.

Predicting appearance esteem rate of change over one year. The results also revealed interactions with time, indicating that some predictors had an effect on the appearance esteem trajectory that differed over time. First, the results indicated a significant general decline in the appearance esteem trajectory over time $(\beta=-0.017, p=0.013)$. Second, an interaction was detected between time and grade levels, which revealed that appearance esteem declined only for Grade 7 students $(\beta=0.017, p=0.016)$. Finally, no significant association was found between mother or father support and change over time in reported appearance esteem, which meant that the effect of mother support and the non-effect of father support on baseline levels of appearance esteem stayed the same at all time points. Nonetheless, the triple interaction was observed between grade levels, social support from friends, and time. Figures 1 and 2 provide a graphical illustration of this interaction for Grade 7 students compared with Grade 10 students receiving high levels

287 (Figure 1) and low levels (Figure 2) of social support from friends. Overall, these results indicate that the grade level modulated the effect of social support from friends on the appearance esteem trajectory. These findings suggest that, among Grade 7 students, even though there was a positive effect of social support from friends on appearance esteem at baseline, it had no effect on the declining appearance esteem trajectory over time. Among Grade 10 students, in addition to its positive effect on appearance esteem at baseline, social support from friends also had a positive effect on the appearance esteem trajectory. This means that receiving a higher level of social support from friends prevented a decline in the appearance esteem trajectory over time. Graphically, even if older students' appearance esteem 294 increased when they had higher levels of social support from friends, their levels of appearance esteem remained below those of younger students over time.

INSERT FIGURES 1 AND 2 HERE.

Finally, there were no time interactions with gender, perceived figure, or weight-related teasing, suggesting that their effect on appearance esteem remained the same over time. Taken together, these results indicate that the 
appearance esteem trajectory changed for both boys and girls as well as for participants with different perceived shapes, regardless of the number of negative comments received.

\section{Sensitivity Analyses}

Because the data used for this study were from a single-source and self-administered questionnaire, common method variance was possible and therefore examined. Although common method variance is more likely to emerge in simple models (Chang et al., 2010) and therefore less likely in the current study given the complex model used, the Harman's one-factor test was also conducted. The results showed no indication of common method variance. Finally, a multiple regression was conducted with the three social support measures using the Durbin-Watson statistic. This test is used as a diagnostic check for bias resulting from autocorrelation in the data when the residuals are not independent from each other and not linearly auto-correlated (Cohen et al., 2013). The results indicated that the Durbin-Watson statistic was in the recommended range, that is, between 1.5 and 2.5 (Durbin \& Watson, 1971).

\section{Discussion}

Although predictors of body dissatisfaction among adolescents have been examined in several studies, for example, psychological factors (Duchesne et al., 2017) or social influences (Quiles Marcos et al., 2013), less is known about the evolution of appearance esteem and its association with social support from significant sources and with other factors. The present study addressed these gaps by examining the impact of three sources of social support (mother, father, and friends) on the trajectory of adolescents' appearance esteem over a 12-month period above and beyond the effect of personal factors (gender, age, perceived figure, weight-related teasing). The data collection included three waves, making it possible to perform a robust linear analysis of the appearance esteem trajectory. The results confirmed most of the hypotheses regarding the positive effects of social support above and beyond the effects of weight-related comments, perceived current figure, and gender. This work contributes to the application of the tripartite model of influence on adolescents' body image and may help to elucidate social and individual factors that can improve adolescents' well-being and mental health.

\section{Appearance Esteem and Social Support}

The findings indicated that only two of the three sources of social support were associated with the appearance esteem trajectory, that is, mother and friends, but not father, which is consistent with previous studies on body satisfaction, such as the ones by Merianos et al. (2012) and Back (2011). These findings support the notion that perceived emotional and behavioral support from significant sources is a protective factor for own body appreciation 
327 (Stice \& Whitenton, 2002), and as early as possible in youths’ lives, as suggested in the studies by Duru, Balkis, \& 328 Turkdoğan (2019) and Thomann Mitchell (2014).

329 Social support from fathers was also expected to be associated (although less strongly) with appearance esteem 330 over time; however, this was not the case. One explanation that should be tested in future study may be because fathers make fewer comments than mothers about their child's weight (Berge et al., 2016). These differences between mother-

332 child and father-child relationships regarding body image may also be explained by the difference in attachment with 333 parents (Szalai et al., 2017) and in type of influence, where children would be more influenced by modeling than by other types of influence (Quiles Marcos et al., 2013).

Moreover, social support from the mother appeared to be more important than that from friends at the initial measurement time, as found in the study by Merianos et al. (2012) and in a previous longitudinal study reporting that deficits in parental social support, but not in peers' social support, predicted growth in body dissatisfaction for both boys and girls (Bearman et al., 2006). Nonetheless, for Grade 10 students, the impact of friends’ support on appearance esteem appeared to change over time. Indeed, friends’ support prevented a decline in the appearance esteem trajectory during the school year for Grade 10 students, supporting the notion that friends can be an important source of influence on adolescents' appearance esteem (Carey et al., 2013). This finding may support the notion that this transition occurs 342 in the period of middle to late adolescence, not from early to middle adolescence (De Goede et al., 2009). Further 343 studies should be conducted to better identify this transition. Participants reporting high levels of social support from friends also reported high levels of social support from

345 parents. This is consistent with the study by Schneider, Atkinson, and Tardif (2001), who proposed that relationship skills would likely be generalized from parent-child relationships to friendships during adolescence. These results may

347 be explained by adolescents’ need for support and reassurance in a positive and secure family environment, despite 348 their need to gain more physical, social, and psychological independence. Thus, even if adolescents spend less time overall with their family during adolescence, the time that they do spend with their mothers and fathers is important for their development and entertainment (Coleman, 2011). These findings together support the hypothesis that social

351 support is related to appearance esteem over time, suggesting that social support plays a key role in appearance esteem 352 during adolescence. Even though the study was not intended to examine the mechanism underlying the link between potential mediators and appearance esteem, those findings may be explained by the fact that social support contributes 
to a more positive self-esteem and self-image, which, in turn, may positively influence how adolescents feel about their appearance, as previously suggested (Sira \& White, 2010).

\section{Appearance Esteem Trajectory}

Another goal of the current study was to investigate the appearance esteem trajectory over one school year. The analyses revealed that, over time, appearance esteem decreased only among participants in Grade 7 . This finding suggests that entry into adolescence may have unfavorable effects on appearance esteem, which is consistent with findings on the negative impact of puberty on body image, as in the studies by Ackard and Peterson (2001) and Tremblay and Lariviere (2009). Appearance esteem also decreased in Grade 10 participants who reported low social support from friends, which suggests a protective role of friends at this age (Kirsch, Shapiro, Conley, \& Heinrichs, 2016).

Regarding associations with other control variables, as hypothesized, female adolescents reported being less satisfied with their appearance than male adolescents, and this difference remained over the one-year study period, which is consistent with previous studies by Abbott, Barber and Dziurawiec (2012) and Bucchianeri et al. (2013). Moreover, a previous 11-year longitudinal study indicated that appearance esteem declined during the transition to adulthood for people of both genders, but that this trend was more pronounced among girls (Frisén et al., 2015). In another study where appearance esteem was compared among young people between the ages of 15 and 20, the results revealed that boys had higher appearance esteem than girls, but that the gap decreased with age (Nanu, Tăut, \& Băban, 2013). In the current study, while the period was only 12 months, no significant interaction was found between time and gender, supporting the notion that people continue to be dissatisfied in the same manner, independently of gender, as proposed in a previous study (Juli, 2017).

Consistent with the third hypothesis, adolescents' appearance esteem was found to be significantly related to every control variable at baseline, and these effects remained the same over time, except for grade level. A larger perceived figure was associated with poorer appearance esteem. As expected, considering that perceived figure is a proxy variable for BMI, these findings are consistent with a previous study also indicating that higher BMI is linked with poorer appearance esteem (Bucchianeri et al., 2013). In addition, weight-related teasing, as expected, was negatively associated with appearance esteem, which supports the importance of the influence of significant others' values on body image (Ata et al., 2007). This finding is also consistent with previous suggestions that this type of 
comment in adolescence is associated with objectified body consciousness and eating disorders over time (Olvera et al., 2016).

As the use of multilevel growth modeling analysis is relatively recent in the field, there are few studies available for comparison. However, it is important to consider that other social factors may also influence appearance esteem. For example, a previous study showed that individual adolescents' characteristics, such as gender, BMI, and general self-esteem, moderated the prediction associations between weight-related comments and social comparison, and body dissatisfaction over time (Cantin \& Stan, 2010). Moreover, personal factors, such as anxiety, comparison tendencies, and internalization of social ideals, can moderate parental influence (Rodgers \& Chabrol, 2009).

\section{Study Strengths and Limitations}

Nevertheless, this study had some limitations that should be considered. Although the sample size was sufficient to test the hypotheses of this study (Coertjens et al., 2017), it was not large enough to provide statistical power to test other moderation hypotheses. For example, a previous study found that gender did not moderate the relationship between social support from family and from peers and body dissatisfaction (Kirsch et al., 2016). Even if a previous study suggested that body satisfaction of offspring is more influenced by parents of the same sex as them (Kluck, 2010), having a larger sample would have allowed parent-adolescent differential gender analyses (i.e., motherdaughter, mother-son, father-daughter, and father-son) to be conducted. Another limitation is that the current data were based on self-reports provided by a single source (the students themselves), creating the possibility of common method variance. In addition, the social support questions precluded knowing exactly to whom the adolescents were referring. However, given that a large majority still lived with their two parents, it was supposed that it was their mother or father. Future research should collect data from multiple respondents (mother, father, and friends) regarding the social support they perceived to be offering. Finally, it may be helpful to examine negative behaviors of adolescents' social groups in future studies, considering that appearance esteem and eating concerns are reported to be negatively influenced by having social support from parents, friends, or significant others who regularly make negative comments about their body or follow diets (Quiles Marcos et al., 2013).

Beyond these measurement issues and sample biases, an important strength of this research is the longitudinal design used, combined with a robust and appropriate statistical technique, multilevel growth modeling (Hedeker, 2004), which overcome the limitations of other statistical methods (Burchinal et al., 2006). Overall, current knowledge suggests that this is the first longitudinal study where a multivariable model was used to predict the trajectory of 
appearance esteem according to social support, allowing the assessment of longitudinal observations of adolescents' life realities. Furthermore, this study addressed gaps in the literature by examining the effects of various sources

411 simultaneously (i.e., mother, father, and friends) and by adding information about fathers' influence on their

412 offspring's body image. Despite the difficulty of collecting anonymous data in several waves and merging them

413 together using a self-generated code, a low rate of attrition was achieved, even if code inconsistencies caused the loss

414 of a small number of participants at T2 and T3. Nonetheless, the risk of bias was greatly diminished given that attrition

415 analyses indicated that no variable predicted dropout as well as by the use of FIML, which can accurately estimate coefficients of participants with missing data points (Johnson \& Young, 2011). As well, for growth models, the bias

417 is less pronounced for the mean slope compared to the variance or covariances, which is often more relevant for the research practitioner (Coertjens et al., 2017). Moreover, the findings from this study add to the acceptance model by providing more information on whether and how support from others can be associated with appearance esteem.

\section{Conclusion}

Several authors have investigated protective and risk factors of body satisfaction among adolescents, but none

422 had yet explored the influence of social support on appearance esteem, let alone on its evolution over a one-year 423 period. The present study addresses this gap by providing longitudinal data regarding three important sources of social 424 support (mother, father and friends) on appearance esteem within an adolescent population over one year, and by 425 exploring individual characteristics that may influence its trajectory. Overall, the results indicated that mothers' and 426 friends’ support are significantly associated with adolescents' appearance esteem over one year. Being female, being 427 in middle adolescence, having a larger self-perceived figure, and receiving negative weight-related comments from a 428 higher number of sources were associated with poorer appearance esteem. Thus, the findings revealed that perceiving 429 high levels of social support from significant sources can be a protective factor for appearance esteem in adolescence 430 and may thus be key in adolescents' adjustment and mental health. Further studies should also be conducted to better 431 understand the fathers' role in this equation.

These results have practical implications and support the idea that schools and families can help promote 433 healthy body image through education and by reducing weight-related teasing. For example, prevention programs 434 should target parents to make them more aware of the impact that their support may have, even indirectly, on their adolescents’ appearance esteem. School programs should also highlight the importance of friends’ support for older

436 adolescents and how it can become a positive agent for a healthy and positive body image. The mediators of 
appearance esteem during adolescence should be examined in future studies to better understand the process of improving appearance esteem through social support. Identifying protective factors and highlighting the importance of adolescents' social groups for the promotion of a healthy body image may help clarify the influence processes of appearance esteem.

\section{Acknowledgments}

INSERT ACKNOWLEDGEMENTS HERE.

\section{References}

Abbott, B. D., Barber, B. L., \& Dziurawiec, S. (2012). What difference can a year make? Changes in functional and aesthetic body satisfaction among male and female adolescents over a year. Australian Psychologist, 47(4), 224-231. https://doi.org/10.1111/j.1742-9544.2011.00057.x

Ackard, D. M., \& Peterson, C. B. (2001). Association between puberty and disordered eating, body image, and other psychological variables. International Journal of Eating Disorders, 29(2), 187-194. https://doi.org/10.1002/1098-108X(200103)29:2<187::AID-EAT1008>3.0.CO;2-R

Arend, M. G., \& Schäfer, T. (2019). Statistical power in two-level models: A tutorial based on Monte Carlo simulation. Psychological methods, 24(1), 1. https://doi.org/10.1037/met0000195

Ata, R. N., Ludden, A. B., \& Lally, M. M. (2007). The effects of gender and family, friend, and media influences on eating behaviors and body image during adolescence. Journal of Youth and Adolescence, 36(8), 1024-1037. https://doi.org/10.1007/s10964-006-9159-x

Avalos, L. C., \& Tylka, T. L. (2006). Exploring a model of intuitive eating with college women. Journal of Counseling Psychology, 53(4), 486-497. https://doi.org/10.1037/0022-0167.53.4.486

Back, E. A. (2011). Effects of parental relations and upbringing in troubled adolescent eating behaviors. Eat Disord, 19(5), 403-424. https://doi.org/10.1080/10640266.2011.609091

Bearman, S. K., Presnell, K., Martinez, E., \& Stice, E. (2006). The skinny on body dissatisfaction: A longitudinal study of adolescent girls and boys. Journal of Youth and Adolescence, 35(2), 229-241. https://doi.org/10.1007/s10964-005-9010-9

Beesdo, K., Bittner, A., Pine, D. S., Stein, M. B., Hofler, M., Lieb, R., \& Wittchen, H.-U. (2007). Incidence of social anxiety disorder and the consistent risk for secondary depression in the first three decades of life. Archives of General Psychiatry, 64(8), 903-912. https://doi:10.1001/archpsyc.64.8.903

Bell, B. A., Ene, M., Smiley, W., \& Shonenberger, J. A. (2013). A multilevel primer using SAS® PROC MIXED. SAS Global Forum. http://support.sas.com/resources/papers/proceedings13/433-2013.pdf

Berge, J. M., Hanson-Bradley, C., Tate, A., \& Neumark-Sztainer, D. (2016). Do parents or siblings engage in more negative weight-based talk with children and what does it sound like? A mixed-methods study. Body Image, 18, 27-33. https://doi.org/https://doi.org/10.1016/j.bodyim.2016.04.008

Bowlby, J. (1978). Attachement et perte. 3 vol., Paris, France: Presses Universitaires de France.

Brown, B. B., Bakken, J. P., Ameringer, S. W., \& Mahon, S. D. (2008). A comprehensive conceptualization of the peer influence process in adolescence. In M. J. Prinstein \& K. A. Dodge (Eds.), Duke series in child development and public policy. Understanding peer influence in children and adolescents (p. 17-44). The Guilford Press.

Bucchianeri, M. M., Arikian, A. J., Hannan, P. J., Eisenberg, M. E., \& Neumark-Sztainer, D. (2013). Body dissatisfaction from adolescence to young adulthood: Findings from a 10-year longitudinal study. Body Image, 10(1), 1-7. https://doi.org/10.1016/j.bodyim.2012.09.001

Burchinal, M. R., Nelson, L., \& Poe, M. (2006). Best practices in quantitative methods for developmentalists: IV. Growth curve analysis: an introduction to various methods for analyzing 
longitudinal data. Monographs of the Society for Research in Child Development, 71(3), 65-87. https://doi: 10.1111/j.1540-5834.2006.00405.x

Camara, M., Bacigalupe, G., \& Padilla, P. (2014). The role of social support in adolescents: Are you helping me or stressing me out? International Journal of Adolescence and Youth, 22(2), 123-136. https://doi.org/10.1080/02673843.2013.875480

Cantin, S., \& Stan, S. N. (2010). Les relations avec les pairs à l'adolescence comme facteurs de risque de l'insatisfaction à l'égard de l'image corporelle [Peer relations in adolescence as risk factors for body image dissatisfaction]. Canadian Journal of Behavioural Science / Revue canadienne des sciences du comportement, 42(2), 116-126. https://doi.org/10.1037/a0016347

Carey, R. N., Donaghue, N., \& Broderick, P. (2013). Peer culture and body image concern among Australian adolescent girls: A hierarchical linear modelling analysis. Sex Roles, 69(5-6), 250-263. https://doi.org/10.1007/s11199-013-0305-0

Cash, T. F. (2012). Encyclopedia of body image and human appearance (Vol. 1-2). United States: Academic Press. https://doi.org/10.1016/C2010-1-66177-9

Coertjens, L. C., Donche, V. C., De Maeyer, S. C., Vanthournout, G. C., Van Petegem, P. C., \& Wicherts, J. M. E. (2017). To what degree does the missing-data technique influence the estimated growth in learning strategies over time? A tutorial example of sensitivity analysis for longitudinal data. PLOS ONE, 12(9). https://doi: 10.1371/journal.pone.0182615

Coleman, J. C. (2011). The nature of adolescence (4th ed.). London: Routledge.

Collins, M. E. (1991). Body figure perceptions and preferences among preadolescent children. International Journal of Eating Disorders, 10(2), 199-208. https://doi.org/10.1002/1098108X(199103)10:2<199::AID-EAT2260100209>3.0.CO;2-D

Daveluy, C., Pica, L., Audet, N., Courtemanche, R., Lapointe, F., Côté, L., \& Bauline, J. (2001). Enquête sociale et de santé 1998 - cahier technique et méthodologique : documentation générale, volume 1.https://bdso.gouv.qc.ca/docsken/multimedia/PB01600FR_Enq1998_documentation2001T04F0 $0 . \mathrm{pdf}$

De Goede, I. H., Branje, S. J., Delsing, M. J., \& Meeus, W. H. (2009). Linkages over time between adolescents' relationships with parents and friends. J Youth Adolesc, 38(10), 1304-1315. https://doi.org/10.1007/s10964-009-9403-2

Deschesnes, M., Schaefer, C., \& Couture, D. (1997). Styles de vie des jeunes du secondaire en Outaouais. Tome 11 (secteur général).http://www.santecom.qc.ca/bibliothequevirtuelle/hyperion/2920780468.pdf

Duchesne, A. P., Dion, J., Lalande, D., Begin, C., Emond, C., Lalande, G., \& McDuff, P. (2017). Body dissatisfaction and psychological distress in adolescents: Is self-esteem a mediator? $J$ Health Psychol, 22, 1563-1569. https://doi.org/10.1177/1359105316631196

Durbin, J., \& Watson, G. S. (1971). Testing for serial correlation in least squares regression. III. Biometrika, 58(1), 1-19. https://doi.org/10.1093/biomet/58.1.1

Duru, E., Balkis, M., \& Turkdoğan, T. (2019). Relational violence, social support, self-esteem, depression and anxiety: A moderated mediation model. Journal of Child and Family Studies, 28(9), 24042414. https://doi.org/10.1007/s10826-019-01509-2

Eisenberg, M. E., Franz, R., Berge, J. M., Loth, K. A., \& Neumark-Sztainer, D. (2017). Significant others' weight-related comments and their associations with weight-control behavior, muscle-enhancing behavior, and emotional well-being. Families, Systems \& Health: The Journal of Collaborative Family Healthcare, 35(4), 474-485. https://doi.org/10.1037/fsh0000298

Eisenberg, M. E., Neumark-Sztainer, D., \& Story, M. (2003). Associations of weight-based teasing and emotional well-being among adolescents, 157(8), 733-738. https://doi.org/10.1001/archpedi.157.8.733

Enders, C. K. (2011). Analyzing longitudinal data with missing values. Rehabilitation Psychology, 56(4), 267.

Gardner, R. M., \& Brown, D. L. (2010). Body image assessment: A review of figural drawing scales. Personality and Individual Differences, 48(2), 107-111. https://doi.org/10.1016/j.paid.2009.08.017 
566

567

568

569

570

571

572

573

574

575

576

577

578

579

580

581

582

583

Gattario, K. H., \& Frisén, A. (2019). From negative to positive body image: Men’s and women’s journeys from early adolescence to emerging adulthood. Body Image, 28, 53-65. https://doi.org/10.1016/j.bodyim.2018.12.002

Graber, J. A., Archibald, A. B., \& Brooks-Gunn, J. (1999). The role of parents in the emergence, maintenance, and prevention of eating problems and disorders. In N. Piran, M. P. Levine, \& C. Steiner-Adair (Eds.), Prevention of eating disorders: A handbook of intervention and special challenges (pp. 44-62). Philadelphia, PA: Brunner/Mazil.

Grimm, K. J., Ram, N., \& Estabrook, R. (2017). Growth modeling: Structural equation and multilevel modeling approaches. New York, NY: Guilford Publications.

Fallon, E. A., Harris, B. S., \& Johnson, P. (2014). Prevalence of body dissatisfaction among a United States adult sample. Eating Behaviors, 15(1), 151-158. https://doi: 10.1016/j.eatbeh.2013.11.007

Frisén, A., Lunde, C., \& Berg, A. I. (2015). Developmental patterns in body esteem from late childhood to young adulthood: A growth curve analysis. European Journal of Developmental Psychology, 12(1), 99-115. https://doi.org/10.1080/17405629.2014.951033

Handford, C. M., Rapee, R. M., \& Fardouly, J. (2018). The influence of maternal modeling on body image concerns and eating disturbances in preadolescent girls. Behaviour Research and Therapy, 100, 1723. https://doi.org/10.1016/j.brat.2017.11.001

Hardit, S. K., \& Hannum, J. W . (2012). Attachment, the tripartite influence model, and the development of body dissatisfaction. Body Image, 9(4), 469-475. https://doi.org/10.1016/j.bodyim.2012.06.003

Hedeker, D. (2004). An introduction to growth modeling. The Sage handbook of quantitative methodology for the social sciences, 215-234.

Hoffman, L. (2007). Multilevel models for examining individual differences in within-person variation and covariation over time. Multivariate Behavioral Research, 42(4), 609-629. https://doi.org/10.1080/00273170701710072

Johnson, D. R., \& Young, R. (2011). Toward best practices in analyzing datasets with missing data: Comparisons and recommendations. Journal of Marriage and Family, 73(5), 926-945. https://doi.org/10.1111/j.1741-3737.2011.00861.X

Jones, D. C., Vigfusdottir, T. H., \& Lee, Y. (2004). Body image and the appearance culture among adolescent girls and boys: An examination of friend conversations, peer criticism, appearance magazines, and the internalization of appearance ideals. Journal of Adolescent Research, 19(3), 323-339. https://doi.org/10.1177/0743558403258847

Juli, M. R. (2017). Perception of body image in early adolescence. An investigation in secondary schools. Psychiatria Danubina, 29(Suppl 3), 409-415.

Kenny, U., O'Malley-Keighran, M.-P., Molcho, M., \& Kelly, C. (2017). Peer influences on adolescent body image: Friends or foes? Journal of Adolescent Research, 32(6), 768-799. https://doi:10.1177/0743558416665478

Kirsch, A. C., Shapiro, J. B., Conley, C. S., \& Heinrichs, G. (2016). Explaining the pathway from familial and peer social support to disordered eating: Is body dissatisfaction the link for male and female adolescents? Eating Behaviors, 22, 175-181. https://doi.org/10.1016/j.eatbeh.2016.06.018

Kluck, A. S. (2010). Family influence on disordered eating: The role of body image dissatisfaction. Body Image, 7(1), 8-14. https://doi.org/10.1016/j.bodyim.2009.09.009

Littleton, H. L., \& Ollendick, T. (2003). Negative body image and disordered eating behavior in children and adolescents: What places youth at risk and how can these problems be prevented? Clinical Child \& Family Psychology Review, 6(1), 51-66. https://link.springer.com/article/10.1023/A:1022266017046.

López-Guimerà, G., Neumark-Sztainer, D., Hannan, P., Fauquet, J., Loth, K., \& Sánchez-Carracedo, D. (2013). Unhealthy weight-control behaviours, dieting and weight status: A cross-cultural comparison between North American and Spanish adolescents. European Eating Disorders Review, 21(4), 276. https://doi.org/10.1002/erv.2206

Mendelson, B. K., Mendelson, M. J., \& White, D. R. (2001). Body-esteem scale for adolescents and adults. Journal of Personality Assessment, 76(1), 90-106. https://doi.org/10.1207/S15327752JPA7601_6 
614

615

616

617

618

619

620

621

622

623

624

625

626

627

628

629

630

631

632

633

Merianos, A., King, K., \& Vidourek, R. (2012). Does perceived social support play a role in body image satisfaction among college students? Journal of Behavioral Health, 1(3), 178-184. https://doi.org/10.5455/jbh.20120501101051

Nanu, C., Tăut, D., \& Băban, A. (2013). Appearance esteem and weight esteem in adolescence. Are they different across age and gender? Cognition, Brain, Behavior: An Interdisciplinary Journal, 17(3), 189-200. https://www.researchgate.net/publication/289203475_Appearance esteem and weight esteem i $n$ adolescence are they different across age and gender

Nelson, S. C., Kling, J., Wangqvist, M., Frisen, A., \& Syed, M. (2018). Identity and the body: Trajectories of body esteem from adolescence to emerging adulthood. Developmental Psychology, 54(6), 11591171. https://doi.org/10.1037/dev0000435

Frisén, A., Lunde, C., \& Berg, A. I. (2015). Developmental patterns in body esteem from late childhood to young adulthood: A growth curve analysis. European Journal of Developmental Psychology, 12(1), 99-115. https://doi.org/10.1080/17405629.2014.951033

Olvera, N., McCarley, K., Matthews-Ewald, M. R., Fisher, F., Jones, M., \& Flynn, E. G. (2016). Pathways for disordered eating behaviors in minority girls. The Journal of Early Adolescence, 37(3), 367386. https://doi.org/10.1177/0272431615609155

Parker, G., Tupling, H., \& Brown, L. B. (1979). A parental bonding instrument. British Journal of Medical Psychology, 52(1), 1-10. https://doi.org/10.1111/j.2044-8341.1979.tb02487.x

Quiles Marcos, Y., Quiles Sebastian, M. J., Pamies Aubalat, L., Botella Ausina, J., \& Treasure, J. (2013). Peer and family influence in eating disorders: A meta-analysis. Eur Psychiatry, 28(4), 199-206. https://doi.org/10.1016/j.eurpsy.2012.03.005

Ricciardelli, L. A., \& Yager, Z. (2016). Adolescence and body image: From development to preventing dissatisfaction. Oxfordshire, England: Routledge/Taylor \& Francis Group.

Rodgers, R., \& Chabrol, H. (2009). Parental attitudes, body image disturbance and disordered eating amongst adolescents and young adults: A review. European Eating Disorders Review: The Professional Journal of the Eating Disorders Association, 17(2), 137-151. https://doi.org/10.1002/erv.907

Schaefer, E. S. (1965). Children's reports of parental behavior: An inventory. Child Development, 36(2), 413-424. https://doi.org/10.2307/1126465

Schneider, B. H., Atkinson, L., \& Tardif, C. (2001). Child-parent attachment and children's peer relations: A quantitative review. Dev Psychol, 37(1), 86-100. https://doi.org/10.1037/0012-1649.37.1.86

Siegelman, M. (1965). Evaluation of Bronfenbrenner's questionnaire for children concerning parental behavior. Child Development, 36(1), 163-174. https://doi.org/10.2307/1126788

Singer, J. D., \& Willett, J. B. (2003). Applied longitudinal data analysis: Modeling change and event occurrence. Oxford: Oxford University Press.

Sira, N., \& White, C. P. (2010). Individual and familial correlates of body satisfaction in male and female college students. Journal of American College Health, 58(6), 507-514. https://doi.org/10.1080/07448481003621742

Stice, E., \& Whitenton, K. (2002). Risk factors for body dissatisfaction in adolescent girls: A longitudinal investigation. Developmental Psychology, 38(5), 669-678. https://doi.org/10.1037/00121649.38.5.669

Szalai, T., Czeglédi, E., Vargha, A., \& Grezsa, F. (2017). Parental attachment and body satisfaction in adolescents. Journal of Child \& Family Studies, 26(4), 1007-1017. https://doi.org/10.1007/s10826016-0626-Z

Thomann Mitchell, E. (2014). Difficulties among children exposed to multiple risks and the protective role of social support (Doctoral dissertation). https://www.ideals.illinois.edu/handle/2142/44274

Thompson, J. K., Heinberg, L. J., Altabe, M., \& Tantleff-Dunn, S. (1999). Exacting beauty: Theory, assessment, and treatment of body image disturbance. American Psychological Association. https://doi.org/10.1037/10312-000 
634

635

636

637

638

639

640

641

642

643

644

645

646

647

648

649

650

651

652

653
Tremblay, L., \& Lariviere, M. (2009). The influence of puberty onset, body mass index, and pressure to be thin on disordered eating behaviors in children and adolescents. Eating Behaviors, 10(2), 75-83. https://doi.org/10.1016/j.eatbeh.2008.12.001

Wang, S. B., Haynos, A. F., Wall, M. M., Chen, C., Eisenberg, M. E., \& Neumark-Sztainer, D. (2019). Fifteen-year prevalence, trajectories, and predictors of body dissatisfaction from adolescence to middle adulthood. Clinical Psychological Science, 7(6), 1403-1415. https://doi.org/10.1177\%2F2167702619859331

Wängqvist, M., \& Frisén, A. (2013). Swedish 18-year-olds' identity formation: Associations with feelings about appearance and internalization of body ideals. Journal of Adolescence, 36(3), 485-493. https://doi.org/https://doi.org/10.1016/j.adolescence.2013.02.002

Yurek, L. A., Vasey, J., \& Sullivan Havens, D. (2008). The use of self-generated identification codes in longitudinal research, Evaluation Review, 32(5), 435-452. https://doi.org/10.1177/0193841x08316676

Zhang, Z., \& Wang, L. (2009). Statistical power analysis for growth curve models using SAS. Behavior Research Methods, 41(4), 1083-1094. https://doi.org/10.3758/BRM.41.4.1083

Zimet, G. D., Dahlem, N. W., Zimet, S. G., \& Farley, G. K. (1988). The multidimensional scale of perceived social support. Journal of Personality Assessment, 52(1), 30-41. https://doi.org/10.1207/s15327752jpa5201_2 